\title{
Single-stage VASER-assisted liposuction and lymphatico-venous anastomoses for the treatment of extremity lymphedema: a case series and systematic review of the literature
}

\author{
Pedro Ciudad ${ }^{1,2}$, Oscar J. Manrique ${ }^{3}$, Samyd S. Bustos ${ }^{3}$, Mouchammed Agko ${ }^{4}$, Tony Chieh-Ting Huang ${ }^{3}$, \\ Luis Vizcarra ${ }^{2}$, Marco Lazo Nuñez ${ }^{5}$, Federico Lo Torto ${ }^{6}$, Antonio J. Forte ${ }^{7}$ \\ ${ }^{1}$ Department of Plastic, Reconstructive and Burn Surgery, Arzobispo Loayza National Hospital, Lima, Peru; ${ }^{2}$ Institute of Plastic, Reconstructive \\ and Aesthetic Surgery, Ciruesthetic, Clinic, Lima, Peru; ${ }^{3}$ Department of Plastic and Reconstructive Surgery, Mayo Clinic, Rochester, MN, USA; \\ ${ }^{4}$ Section of Plastic Surgery, Medical College of Georgia, Augusta University, Augusta, GA, USA; ${ }^{5}$ National Institute of Child Health-Breña, Lima, \\ Peru; ${ }^{6}$ Department of Surgery "Pietro Valdoni", Plastic Surgery Unit, Sapienza University of Rome, Rome, Italy; ${ }^{7}$ Department of Plastic and \\ Reconstructive Surgery, Mayo Clinic, FL, USA \\ Contributions: (I) Conception and design: P Ciudad; (II) Administrative support: P Ciudad, OJ Manrique, SS Bustos, AJ Forte; (III) Provision of \\ study materials or patients: P Ciudad, OJ Manrique; (IV) Collection and assembly of data: P Ciudad, OJ Manrique, SS Bustos; (V) Data analysis and \\ interpretation: P Ciudad, OJ Manrique, SS Bustos, M Agko, TC Huang; (VI) Manuscript writing: All authors; (VII) Final approval of manuscript: All \\ authors.
}

Correspondence to: Pedro Ciudad, MD, PhD. Department of Plastic, Reconstructive and Burn Surgery, Arzobispo Loayza National Hospital, Lima, Peru. Email: pciudad@hotmail.com.

Background: A paradigm shift towards the use of combined physiological and excisional surgical approaches for the treatment of lymphedema is permeating the surgical practice worldwide. We describe a single-stage surgical approach combining-vaser assisted liposuction (VAL) and lymphatico-venous anastomoses (LVA) for the treatment of extremity-lymphedema.

Methods: Between March 2018 and March 2019, a retrospective review of patients with extremitylymphedema stage IIb-III International Society of Lymphology who underwent the combined technique was done. Demographics, operative characteristics, clinical outcomes and complications were assessed. Additionally, a systematic review of studies that reported combined physiological procedures with liposuction for the treatment of lymphedema was conducted.

Results: A total of 24 patients [12 upper extremity lymphedema (UEL), and 12 lower extremity lymphedema (LEL)] were included and analyzed. The mean age was 54.5 years (38-72 years). The mean circumference reduction rate was $90 \%$ and $85 \%$ for UEL and LEL, respectively. Infection rate decreased to zero postoperatively in all patients. Ten studies were included in the review: six pooling 220 cases included two-stage procedures, and four pooling 66 cases described one-stage surgeries. All patients who underwent a combined approach reported clinical improvement.

Conclusions: Our combined approach is safe surgical option and allows adequate limb size reduction with faster recovery in selected patients with lymphedema with strong fibroadipose component.

Keywords: Lymphedema; breast cancer lymphedema; suction-assisted lipectomy (SAL); lymphatico-venous anastomoses (LVA)

Submitted Nov 05, 2019. Accepted for publication Dec 12, 2019.

doi: 10.21037 /gs.2020.01.13

View this article at: http://dx.doi.org/10.21037/gs.2020.01.13 


\section{Introduction}

Advanced stages of lymphedema are characterized by excessive subcutaneous fibrosis and hypertrophy of adipose tissues (1). Surgical procedures are indicated in the management of these stages and those refractory to conservative therapies $(2,3)$. Recently, combined surgical approaches, including a debulking and a physiological procedure, have been described in order to address the different pathological components of lymphedema and to improve treatment outcomes $(2,3)$.

Suction-assisted lipectomy (SAL) is an excisional procedure that has been used for the treatment of lymphedema since its introduction by O'Brien in 1989 (4). It has been shown to effectively reduce the lymphedematous limb circumference by removing fibrotic and fatty tissue. The introduction of vibration amplification of sound energy at resonance (VASER) (Sound Surgical Technologies, LLC, Louisville, Col.) technology has enhanced and expanded the use of liposuction and lipoplasty particularly in aesthetic procedures, such as high-definition liposculpture (5-7) and body contouring of fibrous body areas like the back and trunk, and treatment of male and female breast, face and neck. The use of VASER allows a more precise, less traumatic-hence, less painful-procedure with improved outcomes (5). The comparative advantages of this technology allowed us to consider expanding its use for extremity lymphedema, as it facilitates the rupture of subcutaneous fibrotic septa and gentle fragmentation of hypertrophied fat, which is a hallmark of lymphedema.

Patients with lymphedema who have undergone liposuction must adhere to rigorous requirement of postoperative compression to maintain therapeutic results (8-10). Therefore, the combination with a physiological procedure to restore local lymphatic function can theoretically avoid the need for permanent use of compression garments, thus improving quality of life and surgical outcomes.

Different combined protocols have been reported in the literature; however, no consensus has been reached (8,11-13). The aim of this study is to present our experience on the use of VASER-assisted lipectomy (VAL) in combination with lymphatico-venous anastomoses (LVA) as a single-stage procedure to treat moderate-to-severe extremity lymphedema. Herein, we describe the surgical technique, present a case series of this combine approach and analyze the reported literature combining SAL with any physiological surgical procedure.

\section{Methods}

A retrospective chart review of patients who underwent VAL with LVA between March 2018 and March 2019 at Ciruesthetic Clinic in Lima, Peru, was conducted after approval by our institutional review board (IRB). The inclusion criteria for the simultaneous approach of VAL and LVA were as follows: cancer-free patients with lymphedema stage IIb or III International Society of Lymphology (ISL) refractory to conservative management (adjusted diet, exercise regimen and complex decongestive therapy) for a minimum of 12 months. Patients with less than 9 months of follow-up, open wounds or previous surgical treatments for lymphedema were excluded.

Demographic data and clinical photographs both preand post-operatively were documented. Circumferences of both the edematous extremity and the unaffected counterpart pre and at 3, 6 and 12 months postoperative were recorded to calculate the reduction rate. The anatomic landmarks used to measure the circumference were the following: $10 \mathrm{~cm}$ below the elbow or knee, $10 \mathrm{~cm}$ above the wrist or ankle, and at the midhand or midfoot. To calculate the circumference reduction rate, we used the mean of the circumferences measured. We defined the percentage of improvement as "reduction rate" comparing the affected limb (AL) to the healthy limb (HL) using the following equation:

$$
\text { Circumferencereductionrate }(\%)=\frac{[1-(\text { postoperative } A L-H L)}{(\text { pre }- \text { operative } A L-H L)]} \times 100
$$

Surgical characteristics, including operative time, time of VASER device use, liposuction volume, blood loss, and number and location of LVAs were also recorded. Pre and postoperative number of cellulitis episodes were registered. Length of hospital stay and postoperative complications were documented, as well.

Preoperatively, intradermal injections of indocyanine green (ICG) were performed at the second and fourth interdigital spaces of the hand or foot to identify patent distal lymphatic vessels as shown in Figure 1. These sites were identified, marked and respected during the VASER device use and liposuction. 


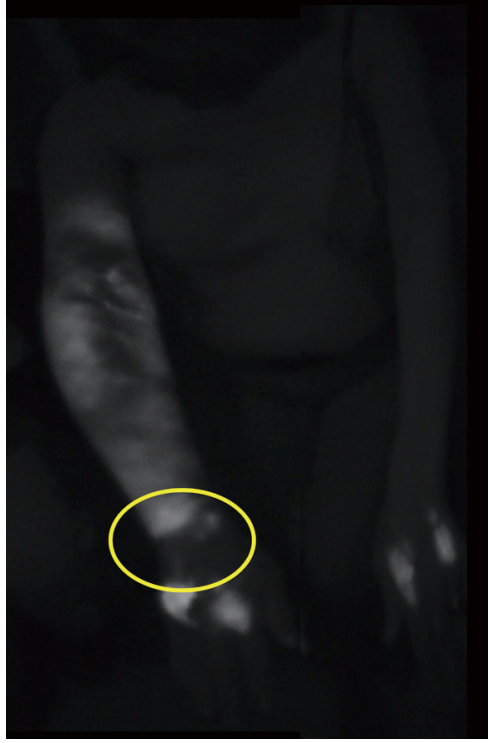

Figure 1 Pre-operative ICG lymphangiography findings in a patient with unilateral secondary lymphedema showing two linear patterns noted at the dorsum of the right hand. The yellow circle shows the transition from a linear pattern to a diffuse-splash pattern located proximal to the wrist, indication lymphatic dysfunction. These areas were respected during the VASER-assisted liposuction in order to perform the lymphaticovenous anastomoses. ICG, indocyanine green; VASER, vibration amplification of sound energy at resonance.

\section{$V A L$}

Under general anesthesia, access incisions of around 4 to 5 $\mathrm{mm}$ in length were marked in the medial and lateral aspects of the wrist and elbow, or ankle and knee, for upper and lower extremity, respectively. Both the VASER-assisted and subsequent liposuction were performed through these incisions. Skin protectors were placed to protect incision edges. A tumescent solution $(1 \mathrm{mg} / \mathrm{mL}$ epinephrine in 1,000 $\mathrm{mL}$ normal saline) was used for infiltration prior to the use of the VASER technology until the extremity was tense to palpation (14). An estimated time of 15 minutes was given after infiltration before the use of VASER to allow adequate distribution of the solution and maximal vasoconstriction.

VAL was performed using a probe with $3.7 \mathrm{~mm}$ diameter and three rings, which allows for a better penetration in fibrous tissues and rapid debulking; see Video 1. VASER continuous mode, which allows a faster fat fragmentation and emulsification, was used.

After the VASER device use, aspiration of emulsified fat deposits and fragmented fibrous tissue was accomplished by conventional liposuction using a $5 \mathrm{~mm}$ cannula. Finally, one or two LVA are performed as close to the transition zone (where the lymphangiographic image changed from linear pattern to an abnormal pattern) as possible at the previously marked sites at the distal aspect of the extremity.

\section{Postoperative care}

All patients were discharged 24 hours postoperatively. Follow-ups in the outpatient clinic were done at 2 weeks, 1, 3, 6 and 12 months postoperatively. Patients were recommended to resume complex decongestive therapy after one week postoperatively to a minimum of 6 months post-operative.

\section{Systematic literature review search methodology}

Applying the Preferred Reporting Items for Systematic Review and Meta-Analysis (PRISMA) (15), a comprehensive literature search was conducted using Ovid MEDLINE, CENTRAL, Ovid Embase, Scopus and Web of Science (WoS) search engines. Search terms were defined using the PICO structure (the search strategy and a complete list of search terms are specified in http://fp.amegroups.cn/cm s/6547b4af07e4991a0916dfe884bef614/gs.2020.01.13-1. pdf): participants $(\mathrm{P})$ included adult patients with extremity lymphedema; the intervention (I) was liposuction in combination with a physiological procedure; comparisons (C) addressed the specific technique used; and outcomes $(\mathrm{O})$ comprised limb measurements, cellulitis, complications, and quality of life.

\section{Systematic review inclusion and exclusion criteria}

All original papers on human studies and in all languages were reviewed to provide a comprehensive compilation of articles. Single case reports and communications were also referenced. Each article was reviewed to verify a liposuction technique was performed together with a physiological procedure, either at the same operative time or as a twostaged procedure. In particular, attention was given towards postoperative surgical outcomes.

\section{Systematic review data extraction}

For all included articles, we documented the following: study characteristics, number of patients, mean age, type 
Table 1 Demographics and clinical information

\begin{tabular}{lcc}
\hline Characteristic & Mean/n & $\begin{array}{c}\text { Range/ } \\
\text { percentage }\end{array}$ \\
\hline Total & 24 & \\
$\quad$ Male & 2 & $8.3 \%$ \\
Female & 22 & $91.7 \%$ \\
Age, years & 54.5 & $38-72$ \\
Body mass index, kg/m ${ }^{2}$ & 26 & $25-32.4$ \\
Etiology & & \\
$\quad$ Breast cancer-related (ULL) & 12 & $50.0 \%$ \\
$\quad$ Gynecologic cancer-related (LLL) & 10 & $41.7 \%$ \\
$\quad$ Urologic cancer-related (LLL) & 2 & $8.3 \%$ \\
Duration of symptoms, months & 24 & $15-40$ \\
Preoperative conservative therapy & 28 & $12-41$ \\
duration, months & & \\
Follow-up, months & 14 & $9-17$ \\
\hline
\end{tabular}

ULL, upper limb lymphedema; LLL, lower limb lymphedema.

and stage of lymphedema, mean follow-up time, type of liposuction, related physiological surgical treatment, and timing between surgical procedures. Outcomes were reported: either circumference difference or reduction rate, or excess volume reduction; cellulitis rate reduction; complications; and quality of life.

\section{Quality assessment}

To assess the risk of bias and quality of design within the included studies, the Newcastle-Ottawa Scale (NOS) (16) for nonrandomized cohort studies and the methodological quality assessment proposed by Murad et al. (17) for case series and reports were used. A maximum of 9 stars or points are awarded to each study in the NOS on items related to the selection of the study (4 points), the comparability of the exposed and unexposed groups ( 2 points), and the ascertainment of outcomes of interest (3 points). For the scale by Murad, a total of 8 points are awarded to each study on items related to the selection (1 point), ascertainment (2 points), causality (4 points), and reporting (1 point).

\section{Statistical analysis}

A narrative synthesis was performed. For our cohort, descriptive analyses with measures of central tendency and dispersion were completed using Microsoft Excel (Microsoft Corporation, Roselle, IL, USA).

\section{Results}

A total of 24 patients ( 2 males and 22 females) were included in this study. Twenty patients had stage IIb and four had stage III International Society of Lymphology (ISL) (18). The mean age and BMI were 54.5 years (range, $38-72$ years) and $26 \mathrm{~kg} / \mathrm{m}^{2}$ (range, $25-32.4 \mathrm{~kg} / \mathrm{m}^{2}$ ), respectively (Table 1). Mean follow-up time was 14 months (range, 9-17 months). All of the 24 patients included had unilateral, secondary lymphedema: 12 breast, 10 gynecologic and 2 urologic cancer-related. Hence, 12 were upper extremity lymphedema (UEL), and 12 were lower extremity lymphedema (LEL). Mean duration of symptoms associated with lymphedema was 24 months (range, 1540 months), and the mean duration of conservative therapy preoperatively was 28 months (range, 12-41 months).

Operative characteristics are summarized in Table 2. Circumference reduction rate was $90 \%(85-98 \%)$ and $85 \%(80-94 \%)$ for UEL and LEL, respectively. The time of VASER device use is illustrated in Figures 2 and 3. Volume of the debulked tissue with liposuction was $1,800 \mathrm{~mL}$ (range, 1,600-2,800 mL) and 2,600 mL (range, 200-3,600 mL) for UEL and LEL, respectively. Blood loss was minimal in both extremities. The number of LVA performed in each procedure varied between 1 and 2. No patient presented with episodes of cellulitis during follow-up. Minor complications, such as postoperative numbness, were reported by all patients, but resolved in less than 5 months, post-operatively. One patient reported epidermolysis, which was treated conservatively and re-epithelized in 3 weeks. All patient s were discharged to home after 24 hours postoperatively. Figures 4 and 5 show clinical pictures of patients who underwent simultaneous VAL and LVA. Figure 6 shows the multilayered compression bandaging used during the first 6 months postoperatively as part of the complex decongestive therapy.

\section{Study retrieval, procedures and characteristics}

Four hundred forty-five citations were identified through the databases searched. A flow diagram outlining the study selection is shown in Figure 7. After duplicates removal, we 
Table 2 Details of the surgical procedure

\begin{tabular}{|c|c|c|c|c|}
\hline Operative characteristic & \multicolumn{2}{|c|}{ Upper limb lymphedema $(n=12)$} & \multicolumn{2}{|c|}{ Lower limb lymphedema (n=12) } \\
\hline Liposuction volume, $\mathrm{mL}$ & 1,800 & $1,600-2,800$ & 2,600 & $200-3,600$ \\
\hline Blood loss, mL & 250 & $150-360$ & 330 & $220-500$ \\
\hline \multicolumn{5}{|l|}{ Time of VASER use, min } \\
\hline Posterior arm/thigh & 6.4 & $5-7$ & 7.5 & $6-8$ \\
\hline Anterior forearm/leg & 4.4 & $3-5$ & 7.5 & $7-8$ \\
\hline Posterior forearm/leg & 5.5 & $4-6$ & 6.4 & $6-8$ \\
\hline Circumference reduction rate, $\%$ & 90 & $85-98$ & 85 & $80-94$ \\
\hline Pre-op, per year & 0.8 & $0-1$ & 1.4 & $1-3$ \\
\hline Post-op, at last follow-up & 0 & & 0 & \\
\hline \multicolumn{5}{|l|}{ Complications } \\
\hline Transient postoperative numbness & 12 & 100 & 12 & 100 \\
\hline Epidermolysis & 0 & 0 & 1 & 8.3 \\
\hline Length of hospital stay, days & 1 & 1 & 1 & 1 \\
\hline
\end{tabular}

VASER, vibration amplification of sound energy at resonance; LVA, lymphatico-venous anastomosis.

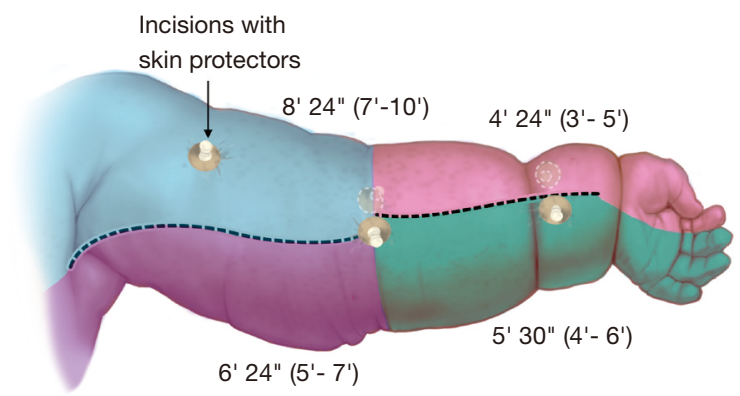

Time of VASER use

Figure 2 Schematic representation of VASER use time in a lymphedematous upper extremity. VASER, vibration amplification of sound energy at resonance.

identified a total of 244 records. Of these, 11 underwent full-text review, and 2 were excluded. A total of 9 studies (8,11-13,19-23) were included for data extraction. Our cohort was also added, yielding a total of 10 studies. In total, these studies represented 286 cases (Table 3). Only one study included patients with primary lymphedema (63 patients, representing $22 \%$ of total cases). Patients were followed for a minimum of 6 months, and one study did not report follow-up time.

Most patients were treated with dry liposuction (a total of 188 patients, representing $65.7 \%$ ), of which 42 (14.7\%) were done conventionally and $146(51 \%)$ were done with the fibro-lipo-lymph-aspiration (FLLA) with a lymph vessel sparing procedure (LVSP) (13) technique, and $2(0.7 \%)$. Only 3 patients $(1 \%)$ were treated with wet liposuction. A total of 95 patients (33.2\%) were treated with tumescent liposuction, of which 64 (22.4\%) were performed conventionally, 10 (3.5\%) laser-assisted, and 24 (8.4\%) VASER-assisted. All reported surgical outcomes, although measurement techniques varied widely among studies.

Six studies, which pool 220 cases, described two staged procedures. Out of these 6 studies, 3 had liposuction performed first and the physiological procedure done in a second operative time [2 vascularized lymph node transfer 
(VLNT), 1 LVA] with 2.5 to 22 months between procedures; whereas, 3 started with the physiological procedure (2 VLNT, 1 LVA) and had liposuction performed 1 to

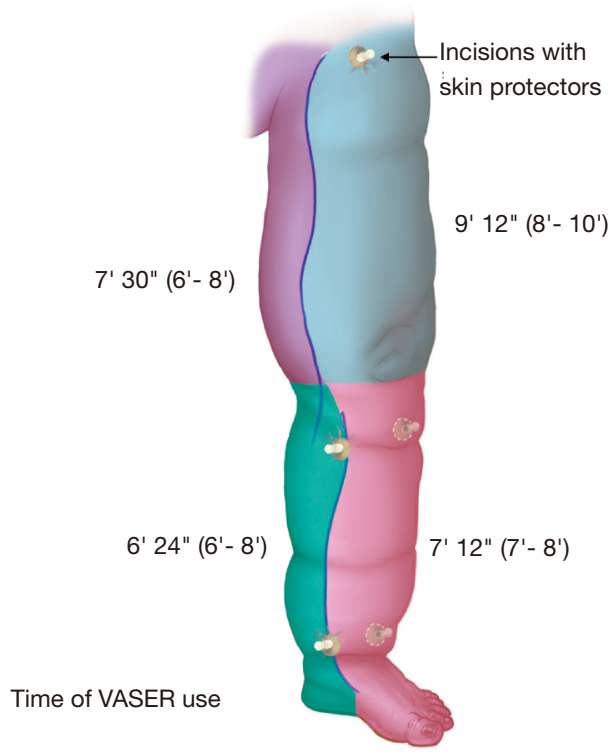

Figure 3 Schematic representation of VASER use time in a lymphedematous lower extremity. VASER, vibration amplification of sound energy at resonance.
11.6 months later. Four studies pooling 66 cases described one-stage procedures. The physiological procedures performed among these were skin or myocutaneous flaps, lymph-fascia grafting, VLNT or LVA.

\section{Outcomes}

A summary of the outcomes reported by each study is presented in Table 4. Measurement techniques to assess surgical outcomes varied in every study, although all showed significant improvement after surgical treatment: six studies represented their outcomes as limb circumference difference or circumference reduction rates; 1 included circumference and volume difference; and 3 measured volume or excess volume (either as percentage or absolute units).

Seven studies measured skin infection episodes reduction after surgery. All reported an overall decrease in skin infection episodes after surgery. In addition, four studies reported complications associated with the surgical procedure. Only two major complications were reported: one patient who underwent two-stage procedure (VLNT as first stage, and tumescent liposuction as second stage) required perioperative blood transfusion; and one patient who underwent a one-stage procedure, VLNT and wet liposuction, required reoperation due to arterial thrombosis. Minor complications reported were transient limb/finger numbness, knee or dorsal foot edema or limited skin

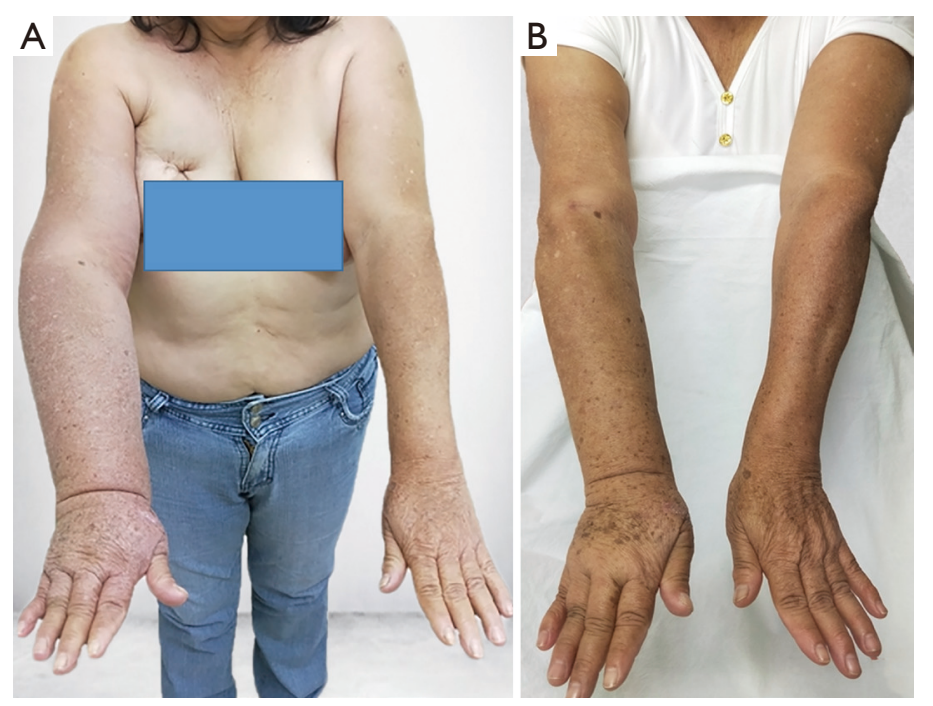

Figure 4 A 59-year-old woman with upper extremity lymphedema who underwent simultaneous VASER-assisted liposuction and distal LVA. (A) Preoperative picture. (B) Postoperative picture at 12 months follow-up showing significant decrease in the size of the affected limb. VASER, vibration amplification of sound energy at resonance; LVA, lymphatico-venous anastomoses. 

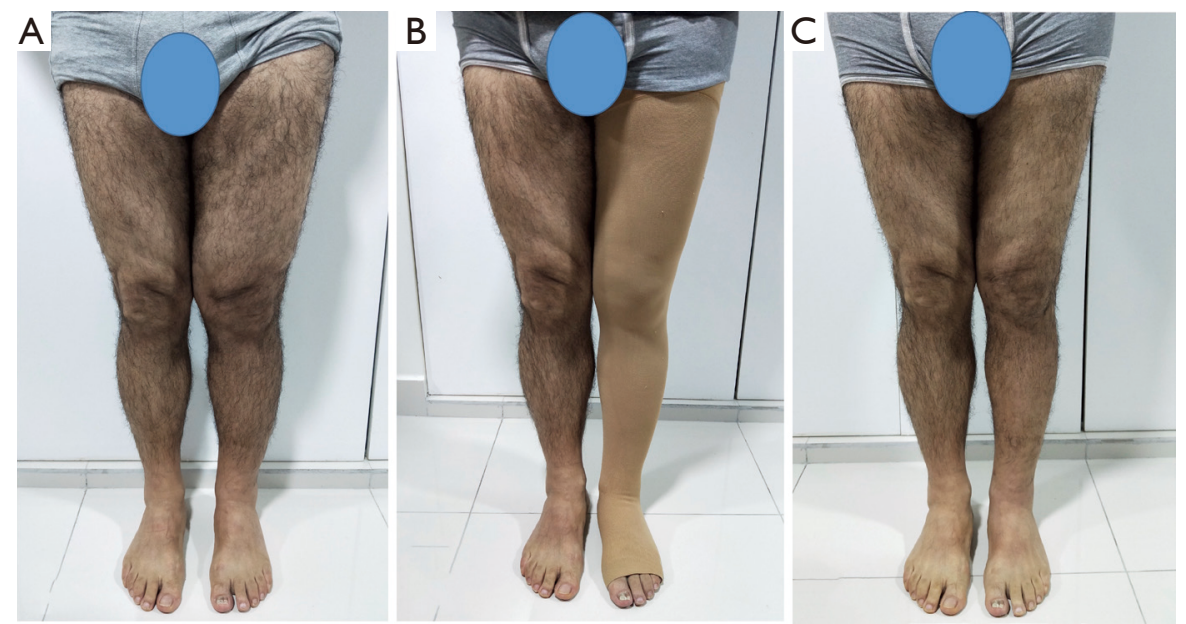

Figure 5 A 56-year-old man with lower extremity lymphedema who underwent simultaneous VASER-assisted liposuction and distal LVA. (A) Preoperative picture. (B) Postoperative picture at 5 months follow-up wearing compression garments. The patient completed 6 months of complex decongestive therapy, after which it was discontinued. (C) Picture at 15 months postoperative showing significant decrease in the size of the affected limb. VASER, vibration amplification of sound energy at resonance; LVA, lymphatico-venous anastomoses.
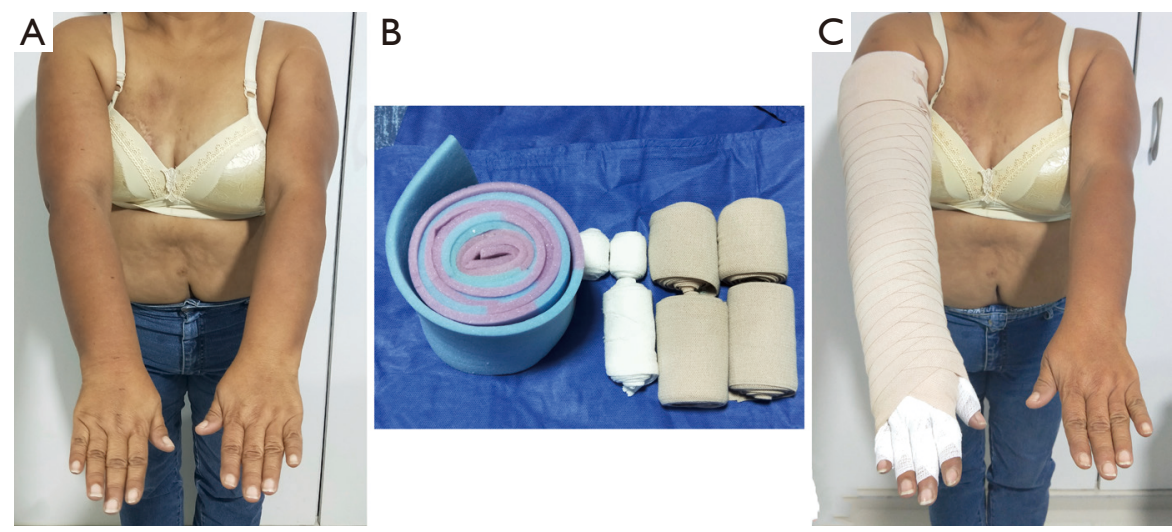

Figure 6 Example of a multi-layered garment used pre-operatively and for the first 6 months post-operatively. Picture shows patient before compression garment placement (A), material used for multilayer garment (B) and after compression garment placement (C).

necrosis.

Quality of life was improved with the use of these surgical approaches. Various studies reported alleviation of symptoms related to lymphedema, including improved limb heaviness and activity. Compression garment use was also reduced or discontinued.

\section{Discussion}

The surgical treatment for lymphedema is generally divided into 2 categories: debulking and physiological procedures. While the purpose of debulking procedures is to alleviate lymphedema burden via removal of all pathological tissues $(24,25)$, physiological procedures aim to restore the aberrant lymphatic drainage system. Liposuction is a debulking procedure; although it is able to provide effective symptomatic relief, patients must adhere to strict lifelong compression therapy as liposuction does not address lymphostasis $(1,26)$. Therefore, the addition of a physiological procedure becomes necessary for a comprehensive surgical management of the fluid component of lymphedema.

Both LVA and VLNT allow the diversion of the lymphatic fluid into the venous system (11). However, the 


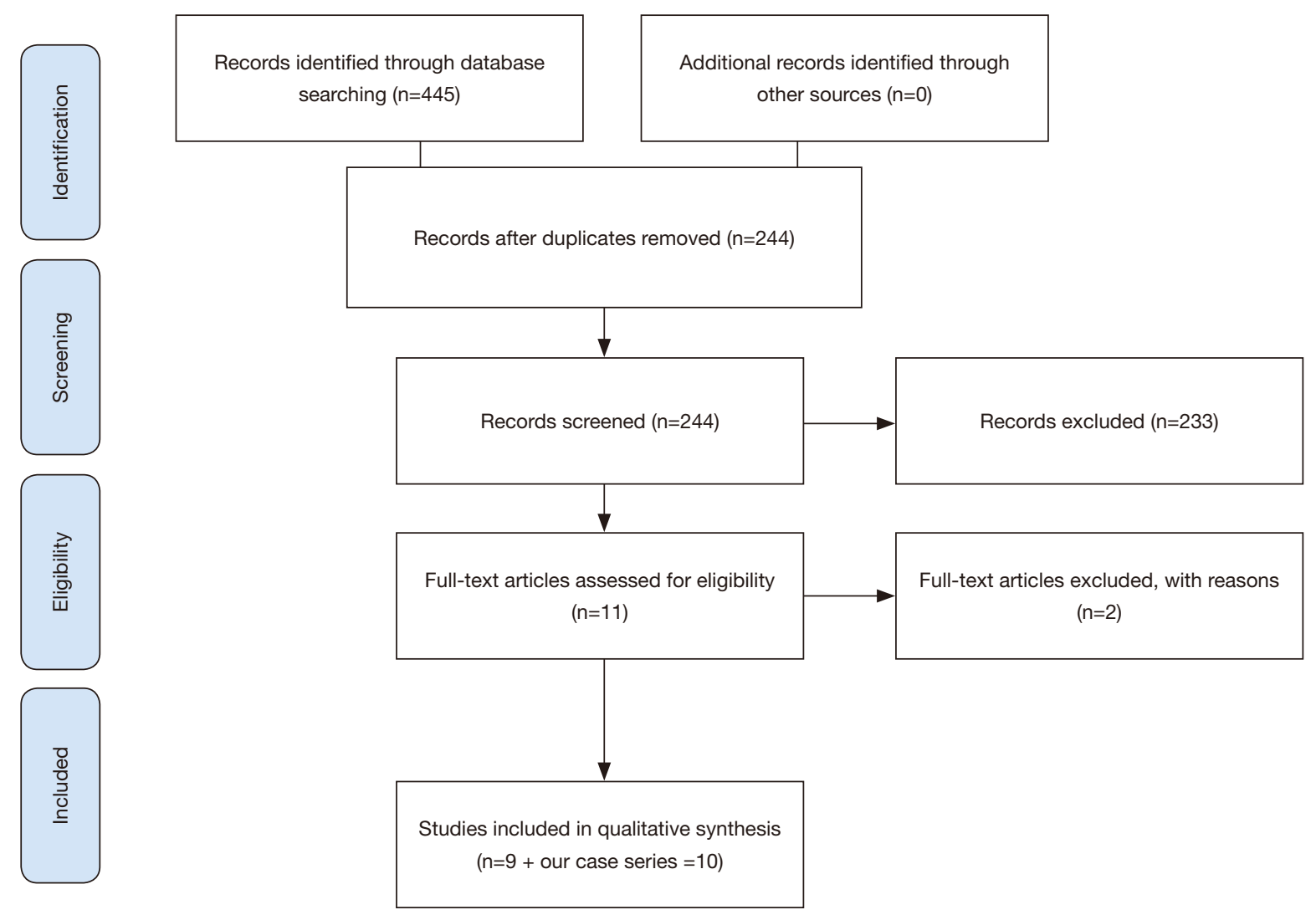

Figure 7 Preferred Reporting Items for Systematic Reviews and Meta-Analyses (PRISMA) flow diagram.

latter entails greater morbidity and complication rates (27). LVA is particularly effective in earlier stages of extremity lymphedema. In a cohort of more than 2,600 patients who underwent multiple LVAs, a significant reduction in excess limb volume of over $84 \%$ was reported. Moreover, over $86 \%$ of patients with early stage lymphedema progressively discontinued conservative therapies, while $42 \%$ with later stages decreased frequency of physical therapies (28). These results suggest additional therapies might be required for later stages.

Although more advanced lymphedema stages are not considered absolute contraindication to LVA for some surgeons $(25,29,30)$, we believe that, for these stages, it is not only necessary to bypass the lymphatic system, but also to address the fibrosis and fat deposition through liposuction. Brorson et al. $(31,32)$ concluded that when the limb volume is dominated by fat, removal of the adipose tissue is a sin equa non for achieving complete volume reduction. In this series of patients, therefore, after performing VAL, we performed one or two LVAs in suitable lymphatic vessels close to the transition zone (from linear to abnormal pattern) identified preoperatively with ICG lymphography at the distal aspect of the extremity. In addition, during dissection, these lymphatic vessels were not skeletonized excessively in order to preserve the wall vascularization and innervation. The rationale of this procedure is that the remaining lymphatic fluid accumulates at the most distal site due to gravitational pull, thus the drainage will be the most effective if bypass is done at the distal site of the lymphangiographic transition zone.

The surgical technique used for liposuction in patients with lymphedema is very different than aesthetic or cosmetic liposuction. Hence, some authors describe it as SAL (26) or suction-assisted protein lipectomy (SAPL) (8). It is usually done circumferentially, step-by-step from distal to proximal $(31,33)$. This procedure was first described by O'Brien et al. (4) in 1989 and since popularized by Brorson (32). Various groups have reported their success using this technique $(9,26)$ with pooled results reporting an excess volume reduction of $96.63 \%$ (86.24-107.02\%) (34). 
Table 3 Studies characteristics

\begin{tabular}{|c|c|c|c|c|c|c|c|c|c|c|}
\hline $\begin{array}{l}\text { Author and } \\
\text { year }\end{array}$ & $\begin{array}{l}\text { Number } \\
\text { of } \\
\text { patients }\end{array}$ & $\begin{array}{l}\text { Average } \\
\text { Age, yr } \\
\text { [range] }\end{array}$ & $\begin{array}{l}\text { Lymphedem } \\
\text { stage }\end{array}$ & $\begin{array}{c}\text { a Lymphedema } \\
\text { type }\end{array}$ & $\begin{array}{l}\text { Lymphedema } \\
\text { site }\end{array}$ & $\begin{array}{l}\text { Average } \\
\text { follow-up, } \\
\text { months } \\
\text { [range] }\end{array}$ & $\begin{array}{c}\text { Type of } \\
\text { liposuction }\end{array}$ & $\begin{array}{c}\text { Related } \\
\text { physiologic } \\
\text { surgical treatment }\end{array}$ & $\begin{array}{l}\text { Timing } \\
\text { between } \\
\text { surgical } \\
\text { treatments }\end{array}$ & NOS \\
\hline $\begin{array}{l}\text { Shi et al. } \\
2003\end{array}$ & 10 & N/A & ND & Secondary & UL & $\begin{array}{c}2 \times 6 \mathrm{mo} \\
7 \times 2 \mathrm{yr} \\
1 \times 4 \mathrm{yr}\end{array}$ & Dry & $\begin{array}{l}\text { Lateral thoracic } \\
\text { skin flap or LD } \\
\text { myocutaneous flap }\end{array}$ & Single-stage & 4 \\
\hline $\begin{array}{l}\text { Granzow } \\
\text { et al. } 2014\end{array}$ & 2 & 59 [55-63] & ND & Secondary & UL & NR & Dry & $\begin{array}{l}\text { Groin VLNT with } \\
\text { proximal inset }\end{array}$ & $\begin{array}{c}\text { First stage: } \\
\text { SAL; second } \\
\text { stage (11-22 } \\
\text { mo later): VLNT }\end{array}$ & $1^{\omega}$ \\
\hline $\begin{array}{l}\text { Cook et al. } \\
2016\end{array}$ & 1 & 52 & $I I I b-I V b^{\beta}$ & Secondary & UL & 12 & Dry & $\begin{array}{l}\text { Supraclavicular } \\
\text { VLNT with distal } \\
\text { inset }\end{array}$ & $\begin{array}{l}\text { First stage: } \\
\text { SAL; second } \\
\text { stage ( } 2.5 \mathrm{mo} \\
\text { later): VLNT }\end{array}$ & $4^{\omega}$ \\
\hline $\begin{array}{l}\text { Campisi } \\
\text { et al. } 2016\end{array}$ & 146 & $\begin{array}{c}\text { NR } \\
{[20-60]}\end{array}$ & $\|l b-\| l \mid b^{\delta}$ & $\begin{array}{l}\text { Primary: } 69 \text {, } \\
\text { secondary: } 77\end{array}$ & $\begin{array}{c}\text { UL: } 63, \mathrm{LL}: \\
83\end{array}$ & At least 12 & $\begin{array}{l}\text { FLLA-LVSP, } \\
\text { dry }\end{array}$ & LVA & $\begin{array}{l}\text { First stage: } \\
\text { LVA; second } \\
\text { stage (5.5-11.6 } \\
\text { mo later): } \\
\text { FLLA-LVSP }\end{array}$ & 5 \\
\hline $\begin{array}{l}\text { Agko et al. } \\
2017\end{array}$ & 12 & 52 [27-72] & $\|^{\alpha}$ & Secondary & UL: 6, LL: 6 & $\begin{array}{c}23.5 \\
{[18-28]}\end{array}$ & Tumescent & $\begin{array}{c}\text { Gastroepiploic } \\
\text { VLNT with both } \\
\text { proximal and distal } \\
\text { inset }^{\mu}\end{array}$ & $\begin{array}{c}\text { First stage: } \\
\text { VLNT; second } \\
\text { I stage (6-8 mo } \\
\text { later): SAL }\end{array}$ & 4 \\
\hline $\begin{array}{l}\text { Leppäpuska } \\
\text { et al. } 2019\end{array}$ & 21 & $\begin{array}{c}56.7 \\
{[37-74]}\end{array}$ & $\mathbb{I}^{\alpha}$ & Secondary & UL & $\begin{array}{c}48.9 \\
{[26-71]}\end{array}$ & $\begin{array}{l}\text { Dry: } 18 \\
\text { Wet: } 3\end{array}$ & Groin VLNT ${ }^{\Omega}$ & Single-stage & 4 \\
\hline $\begin{array}{l}\text { Ciudad } \\
\text { et al. } 2019\end{array}$ & 24 & $\begin{array}{c}54.5 \\
{[38-72]}\end{array}$ & $\left.\|b-\|\right|^{\alpha}$ & Secondary & $\begin{array}{l}\text { UL: } 12, \mathrm{LL}: \\
12\end{array}$ & 14 [9-17] & $\begin{array}{l}\text { Tumescent } \\
\text { VASER- } \\
\text { assisted }\end{array}$ & LVA & Single-stage & 4 \\
\hline
\end{tabular}

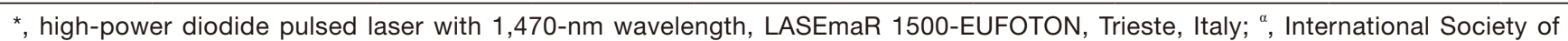
Lymphology Staging System; ${ }^{\beta}$, modified staging system by Karri et al.; ${ }^{\circ}$, campisi staging system; ${ }^{\mu}$, flap was divided extracorporeally into two units and placed proximally and distally; ${ }^{\Omega}$, for 10 patients, this was combined with a lower abdominal flap (DIEP or ms-TRAM flap) for immediate breast reconstruction; ' ${ }^{\circ}$, methodological quality assessment of case report/series proposed by Murad et al. NOS, NewcastleOttawa Scale; ND, not discussed; N/A, not applicable; UL, upper limbs, LL, lower limbs; LD, latissimus dorsi; LVA, lymphatico-venous anastomosis; VLNT, vascularized lymph node transfer; FLLA-LVSP, fibro-lipo-lypmh-aspiration with a lymph vessel sparing procedure; Suction-assisted lipectomy. 


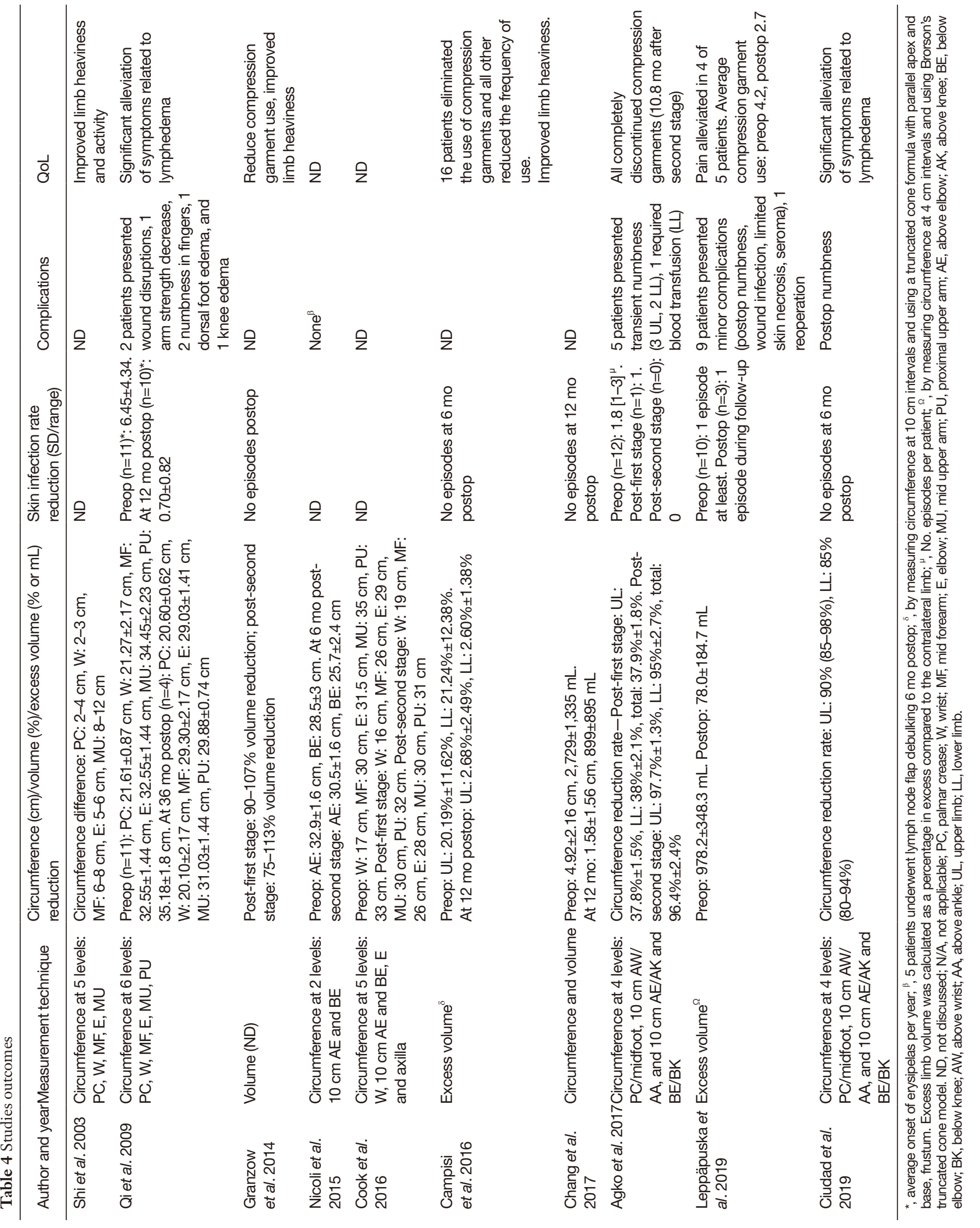


In our systematic review, different wetting solutions were used for liposuction in the treatment of lymphedema: dry, wet and tumescent. In the dry technique, liposuction is performed without the addition of subcutaneous solution injection (35). The wet technique injects hypotonic saline within the subcutaneous tissue with the purpose of theoretically inducing swelling and hydrolysis (lipolysis) (36). Even though the wet technique causes less blood loss than the dry, it is still excessive. Therefore, in order to improve the safety of the liposuction, more surgeons are now using the tumescent technique; it is defined as $2-3 \mathrm{cc}$ of infiltrate per $1 \mathrm{cc}$ of aspirate (37-39). Usually, the infiltrate includes a mixture of lidocaine, adrenaline and normal saline.

The search of higher effectiveness for liposuction in the treatment of lymphedema led to the introduction of laser lipolysis by Nicoli et al. (12). The laser beam allows the creation of smaller channels through tissue, which translates to a less aggressive liposuction, easier penetration, and a more potent single-stage fibro-lipolysis. In addition, it can also be used to release significant scar tissue after axillary dissection (12). The safety of this technique has been well documented; however, burns are one of its major drawbacks due to the narrow window between the accumulation of localized thermal energy that denatures fibrotic tissue and dermal-epidermal thermal injury (40).

With the need of overcoming the problems presented by the current liposuction techniques and to improve the surgical effectiveness, we used the fourth-generation ultrasound lipoplasty device, which uses continuous lowpower ultrasound and high-efficiency, small-diameter solid titanium probes with unique rings and grooves: VASER (41-43). This technology, which is used mainly for aesthetic body contouring and for the high-definition liposuction proposed by Hoyos (42), uses a method for penetrating fatty tissue with ultrasonic energy. This causes the fragmentation of fibrotic tissue and emulsification of fat by three physiological effects: (I) micromechanical effect; (II) cavitational effects produce cell fragmentation and diffusion of the lipid matrix; (III) thermal effect caused by acoustic waves as they pass tissue (42). The ultrasound waves allow the rupture of fibrotic tissue and septa, which not only facilitates extraction, but also preserves vascularization and lymphatic vessels. To decrease the thermal energy produced by the acoustic waves as they traverse tissue, the device includes multiple rings that dissipate the energy in all direction, decreasing the energy emitted through the tip of the probe (42). In addition, we use a tumescent technique (tissue infiltration) to decrease thermal injury even more. This technique reduces the avulsion trauma of the tissues and the postoperative recovery is better; there is less traumatic bruising, sensitivity and better skin draping (42). Indeed, in our cohort, patients were discharged in 24 hours.

Despite its numerous advantages, this technology still has few downsides: it requires a long learning curve, but the ultimate outcome appears to be superior than previous techniques (42). Even though the thermal injury risk is lower than laser-assisted liposuction, it should be considered and prevented by gently advancing the cannula and avoiding prolonged use in the same region. Lymphedema still poses a challenge for the lymphatic surgeon. Surgical management of lymphedema has entered a slow, but steady change in paradigm towards the use of combined surgical approaches in order to comprehensively address the pathophysiological implications of lymphedema. The ideal surgical management of lymphedema implies thoroughly addressing the solid and fluid component of the condition reducing at its minimum the complication rates and ensuring enduring outcomes.

\section{Conclusions}

With the increase in the number of surgical procedures in the armamentarium for the treatment of lymphedema, surgeons and researchers in this field are now driven to find the ideal surgical strategy. Increasingly, the balance leans towards combined surgical procedures. We found that in patients with advanced stage lymphedema, a single-stage surgical procedure including VAL and LVAs is feasible, safe, and adequately allows the reduction of limb size. The findings of this study allow the summary of various techniques, and the use of the described one-stage technique has potentially key implications for the surgical treatment of extremity lymphedema.

\section{Acknowledgments}

The Senior author (PC) would like to thank Su-Jeik Chu, Ingrid Chemaly (MEDI) and Mariana Acuña (MEDI) for their assistance in the physiotherapeutic preparation and treatment of this series of patients.

Funding: None.

\section{Footnote}

Provenance and Peer Review: This article was commissioned 
by the Guest Editors (Xiaona Lu, Antonio Jorge Forte) for the series "Lymphedema" published in Gland Surgery. The article was sent for external peer review organized by the Guest Editors and the editorial office.

Conflicts of Interest: All authors have completed the ICMJE uniform disclosure form (available at http://dx.doi. org/10.21037/gs.2020.01.13). The series "Lymphedema" was commissioned by the editorial office without any funding or sponsorship. AJF served as the unpaid Guest Editor of the series. The other authors have no other conflicts of interest to declare.

Ethical Statement: The authors are accountable for all aspects of the work in ensuring that questions related to the accuracy or integrity of any part of the work are appropriately investigated and resolved. The institutional review board approved the study (CC No: DMR002- IRB112 ) and written informed consent was obtained from all patients.

Open Access Statement: This is an Open Access article distributed in accordance with the Creative Commons Attribution-NonCommercial-NoDerivs 4.0 International License (CC BY-NC-ND 4.0), which permits the noncommercial replication and distribution of the article with the strict proviso that no changes or edits are made and the original work is properly cited (including links to both the formal publication through the relevant DOI and the license). See: https://creativecommons.org/licenses/by-nc-nd/4.0/.

\section{References}

1. Warren AG, Brorson H, Borud LJ, et al. Lymphedema: a comprehensive review. Ann Plast Surg 2007;59:464-72.

2. Ciudad P, Agko M, Huang TCT, et al. Comprehensive multimodal surgical treatment of end-stage lower extremity lymphedema with toe management: The combined Charles,' Homan's, and vascularized lymph node transfer (CHAHOVA) procedures. J Surg Oncol 2019;119:430-8.

3. Ciudad P, Manrique OJ, Adabi K, et al. Combined double vascularized lymph node transfers and modified radical reduction with preservation of perforators for advanced stages of lymphedema. J Surg Oncol 2019;119:439-48.

4. O'Brien BM, Khazanchi RK, Kumar PA, et al. Liposuction in the treatment of lymphoedema; a preliminary report. $\mathrm{Br}$ J Plast Surg 1989;42:530-3.
5. Hoyos AE, Millard JA. VASER-Assisted High-Definition Liposculpture. Aesthet Surg J 2007;27:594-604.

6. Hoyos A. High Definition liposculpture. In: XIII International Course of Plastic Surgery, Bucaramanga, Colombia, 2003. 2003.

7. Fischer G. Liposculpture: the "correct" history of liposuction. Part I. J Dermatol Surg Oncol 1990;16:1087-9.

8. Granzow JW, Soderberg JM, Dauphine C. A novel twostage surgical approach to treat chronic lymphedema. Breast J 2014;20:420-2.

9. Boyages J, Kastanias K, Koelmeyer LA, et al. Liposuction for Advanced Lymphedema: A Multidisciplinary Approach for Complete Reduction of Arm and Leg Swelling. Ann Surg Oncol 2015;22:S1263-70.

10. Schaverien MV, Munnoch DA, Brorson H. Liposuction Treatment of Lymphedema. Semin Plast Surg 2018;32:42-7.

11. Agko M, Ciudad P, Chen HC. Staged surgical treatment of extremity lymphedema with dual gastroepiploic vascularized lymph node transfers followed by suctionassisted lipectomy-A prospective study. J Surg Oncol 2018;117:1148-56.

12. Nicoli F, Constantinides J, Ciudad P, et al. Free lymph node flap transfer and laser-assisted liposuction: a combined technique for the treatment of moderate upper limb lymphedema. Lasers Med Sci 2015;30:1377-85.

13. Campisi CC, Ryan M, Boccardo F, et al. Fibro-lipolymph-aspiration with a lymph vessel sparing procedure to treat advanced lymphedema after multiple lymphaticvenous anastomoses: The complete treatment protocol. Ann Plast Surg 2017;78:184-90.

14. Klein JA. The Tumescent Technique for Lipo-Suction Surgery. Am J Cosmet Surg 1987;4:263-7.

15. Moher D, Liberati A, Tetzlaff J, et al. Preferred Reporting Items for Systematic Reviews and Meta-Analyses: The PRISMA Statement. PLoS Med 2009;6:e1000097.

16. Stang A. Critical evaluation of the Newcastle-Ottawa scale for the assessment of the quality of nonrandomized studies in meta-analyses. Eur J Epidemiol 2010;25:603-5.

17. Murad MH, Sultan S, Haffar S, et al. Methodological quality and synthesis of case series and case reports. BMJ Evid Based Med 2018;23:60-3.

18. The Diagnosis and Treatment of Peripheral Lymphedema: 2016 Consensus Document of the International Society of Lymphology. Lymphology 2016;49:170-84.

19. Leppäpuska IM, Suominen E, Viitanen T, et al. Combined Surgical Treatment for Chronic Upper Extremity Lymphedema Patients: Simultaneous Lymph Node 
Transfer and Liposuction. Ann Plast Surg 2019;83:308-17.

20. Qi F, Gu J, Shi Y, et al. Treatment of upper limb lymphedema with combination of liposuction, myocutaneous flap transfer, and lymph-fascia grafting: a preliminary study. Microsurgery 2009;29:29-34.

21. Cook KH, Park MC, Lee IJ, et al. Vascularized Free Lymph Node Flap Transfer in Advanced Lymphedema Patient after Axillary Lymph Node Dissection. J Breast Cancer 2016;19:92-5.

22. Shi YD, Qi FZ, Zhang XJ, et al. Flap transplantation combined with liposuction to treat upper limb lymphedema after mastectomy. Zhonghua Zheng Xing Wai Ke Za Zhi 2003;19:430-2.

23. Chang K, Xia S, Sun YG, et al. Liposuction combined with lymphatico-venous anastomosis for treatment of secondary lymphedema of the lower limbs: a report of 49 cases. Chung-Hua Wai Ko Tsa Chih 2017;55:274-8.

24. Karri V, Yang MC, Lee IJ, et al. Optimizing outcome of charles procedure for chronic lower extremity lymphoedema. Ann Plast Surg 2011;66:393-402.

25. Campisi C, Campisi C, Accogli S, et al. Lymphedema staging and surgical indications in geriatric age. BMC Geriatr 2010;10:A50.

26. Damstra RJ, Voesten HG, Klinkert P, et al. Circumferential suction-assisted lipectomy for lymphoedema after surgery for breast cancer. Br J Surg 2009;96:859-64.

27. Scaglioni MF, Arvanitakis M, Chen YC, et al. Comprehensive review of vascularized lymph node transfers for lymphedema: Outcomes and complications. Microsurgery 2018;38:222-9.

28. Campisi CC, Ryan M, Boccardo F, et al. A Single-Site Technique of Multiple Lymphatic-Venous Anastomoses for the Treatment of Peripheral Lymphedema: Long-Term Clinical Outcome. J Reconstr Microsurg 2016;32:42-9.

29. Yamamoto T, Yamamoto N, Yoshimatsu H, et al. Factors Associated with Lymphosclerosis. Plast Reconstr Surg 2017;140:734-41.

30. Boccardo F, Fulcheri E, Villa G, et al. Lymphatic microsurgery to treat lymphedema: techniques and indications for better results. Ann Plast Surg 2013;71:191-5.

Cite this article as: Ciudad P, Manrique OJ, Bustos SS, Agko M, Huang TC, Vizcarra L, Nuñez ML, Torto FL, Forte AJ. Singlestage VASER-assisted liposuction and lymphatico-venous anastomoses for the treatment of extremity lymphedema: a case series and systematic review of the literature. Gland Surg 2020;9(2):545-557. doi: 10.21037/gs.2020.01.13
31. Brorson H. Liposuction in arm lymphedema treatment. Scand J Surg 2003;92:287-95.

32. Brorson H, Svensson H. Liposuction combined with controlled compression therapy reduces arm lymphedema more effectively than controlled compression therapy alone. Plast Reconstr Surg 1998;102:1058-67; discussion 1068.

33. Greene AK, Slavin SA, Brorson H. editors. Lymphedema: Presentation, diagnosis, and treatment. Springer, 2015:1-353.

34. Carl HM, Walia G, Bello R, et al. Systematic Review of the Surgical Treatment of Extremity Lymphedema. J Reconstr Microsurg 2017;33:412-25.

35. Fournier PF, Otteni FM. Lipodissection in body sculpturing: the dry procedure. Plast Reconstr Surg 1983;72:598-609.

36. Heymans O, Castus P, Grandjean FX, et al. Liposuction: Review of the Techniques, Innovations and Applications. Acta Chir Belg 2006;106:647-53.

37. Klein JA. Tumescent technique for local anesthesia improves safety in large-volume liposuction. Plast Reconstr Surg 1993;92:1085-98.

38. Rohrich RJ, Beran SJ, Fodor PB. The role of subcutaneous infiltration in suction-assisted lipoplasty: a review. Plast Reconstr Surg 1997;99:514-9.

39. Rohrich RJ, Kenkel JM, Janis JE, et al. An update on the role of subcutaneous infiltration in suction-assisted lipoplasty. Plast Reconstr Surg 2003;111:926-7; discussion 928.

40. McBean JC, Katz BE. Laser lipolysis: An update. J Clin Aesthet Dermatol 2011;4:25-34.

41. de Souza Pinto EB, Chiarello De Souza Pinto Abdala P, Montecinos MacIel C, et al. Liposuction and VASER. Clinics in Plastic Surgery 2006;33:107-15.

42. Hoyos A, Perez ME, Guarin DE, et al. A Report of 736 High-Definition Lipoabdominoplasties Performed in Conjunction with Circumferential VASER Liposuction. Plast Reconstr Surg 2018;142:662-75.

43. well ML, Fodor PB, De Souza Pinto EB, et al. Clinical application of VASER-assisted lipoplasty: A pilot clinical study. Aesthet Surg J 2002;22:131-46. 